\title{
Osteoporozlu Hastalarda Su İçi Egzersizlerin Yararları
}

\author{
Benefits of Aquatic Exercises in Patients with Osteoporosis
}

Ümit Seçil Demirdal

Afyon Kocatepe Üniversitesi, Tıp Fakültesi, Fiziksel Tıp ve Rehabilitasyon Anabilim Dalı, Afyon, Türkiye

\section{Özet}

Osteoporoz, artmış kemik kırılganlığı ve kırık riskine yol açan azalmış kemik gücü ile karakterize bir iskelet sistemi hastalığıdır. Osteoporozun önlenmesinde ve tedavisinde egzersizler önemli bir yer tutmaktadır. Su içi egzersizler (akuatik ya da havuz egzersizleri) kara egzersizlerine alternatif bir yöntemdir. Su fiziksel ve fizyolojik etkileri sayesinde ideal bir egzersiz ortamı sağlar. Osteoporozlu hastalarda su içi egzersizlerin etkilerini araştıran çalışmalar sınırlı sayıda olmakla beraber bu çalışmalar bize; su içi egzersizlerin kemik yoğunluğunda idame ya da artış eğilimi sağladığını, yaşam kalitesini arttırdığını ve dengeyi iyileştirerek düşme riskini azalttığını göstermiştir. Bu nedenle özellikle düşme korkusu, denge bozuklukları, ağrı ya da motivasyon eksikliği gibi nedenlerle kara egzersizlerini yapmakta zorlanan osteoporozlu hastalar için su içi egzersizler tedavi programına eklenebilir. (Türk Osteoporoz Dergisi 2012;18:37-9)

Anahtar kelimeler: Osteoporoz, egzersiz, su içi egzersiz

\section{Summary}

Osteoporosis is a skeletal disease characterized by decreased bone mass predisposing to increased bone fragility and fracture risk. Exercise has an important role in preventing and management of osteoporosis. Aquatic exercise (water or pool exercise) is an alternative to land-based exercise. Water provides an ideal environment through its physical and physiological properties. Although there are limited studies investigating the effects of aquatic exercises on osteoporosis, these studies show that aquatic exercises provide tendency to increase or maintain bone density levels, quality of life, and reduce the fall risk by enhancing the balance. Aquatic exercises may be added to the treatment regimens especially for individuals who are failed to exercise on land due to the fear of falling, poor balance, pain conditions, or lack of motivation. (Turkish Journal of Osteoporosis 2012;18:37-9)

Key words: Osteoporosis, exercise, aquatic exercise

\section{Giriş}

Osteoporoz (OP), artmış kemik kırılganlığı ve kırık riskine yol açan azalmış kemik gücü ile karakterize bir iskelet sistemi hastalığıdır. Kemik kütlesinde azalma ve kemik mikro mimarisinde bozulma ile sonuçlanan anormal bir süreç söz konusudur. Tanı için altın standart dual X-ray absorbsiyometri (DXA) ile kemik mineral yoğunluğunun (KMY) ölçülmesidir. OP'un en önemli klinik sonucu kırık gelişimidir. El bileği, kalça ya da vertebral kırıklar için ömür boyu risk yaklaşık \%30-40 arasındadır ve bu oran neredeyse koroner arter hastalığı riskine eşittir (1-3).

OP yaşla ilişkili bir hastalıktır ve kadınlar erkeklerden daha fazla etkilenir. Dünya Sağlık Örgütü (DSÖ) sınıflamasına göre, postmenopozal kadınların \%30 kadarında OP gelişmesi beklenmektedir. Yaşlı popülasyonun artmasıyla birlikte OP prevalansının, beraberinde medikal, sosyal ve ekonomik yükünün artması kaçınılmazdır. Bu nedenle OP’un önlenmesi ve tedavisi önemli bir halk sağlığı sorunudur $(2,3)$.

OP tedavisi farmakolojik ve non-farmakolojik yöntemlerden oluşmaktadır. Sigarayı bırakma, alkol kullanımından kaçınma, çevre düzenlemesi gibi non-farmakolojik yöntemlerin içerisinde egzersizler de yer alır. Yük bindirici, aerobik ve dirençli egzersizlerin omurga KMY üzerinde etkili olduğu gösterilmiştir (3). Son veriler, OP tedavisinde en etkili egzersiz tiplerinin, femur boynu KMY için progresif dirençli güçlendirme egzersizlerinin; omurga KMY için ise kombine egzersiz programlarının (statik-dinamik yük bindirici, düşük ve yüksek güçlü yük bindirmeyen egzersizlerin kombinasyonları) olduğunu göstermiştir (4). 


\section{Su İçi Egzersizler}

Su içi egzersizler, kara egzersizlerine alternatif bir yöntemdir. Bunun yanında "havuz egzersizleri" ve "'akuatik egzersizler" terimleri de aynı anlamda kullanılmaktadır. Su içi egzersizler amaca yönelik inşa edilmiş, uygun ısı ve derinlikteki havuzlarda, bireye ve hastalığa özel uygulanır. Bu egzersizlerde suyun hem fiziksel, hem de fizyolojik özelliklerinden faydalanılır.

Suyun ısınma kapasitesi birçok maddeden yüksektir ve aynı zamanda su iyi bir ısı ileticisidir. Su ısısının vücuda iletilmesi ile ağııda azalma, spazmda çözülme, eklem hareket açıklıklarında ve eklem esnekliğinde artış sağlanır (5). Suyun en önemli özelliklerinden biri de "Arşimed Prensibi" ile açıklanan kaldırma kuvvetidir. Suyun kaldırma kuvveti sayesinde eklemlere binen yük azalır ve eklem hareket açıkığını artar. Kara egzersizlerine göre daha erken, güvenli ve daha ağrısız rehabilitasyon imkanı doğar. Su egzersizleri omurgaya ve diğer eklemlere binen yükü azaltarak postural düzeltmelerin daha kolay uygulanmasına olanak verir. Suyun yüzeyindeki gerilim ve su molekülleri arasında oluşan iç sürtünme (viskozite), su direncini oluşturur. Su direnci de, suyun ideal bir egzersiz ortamı oluşturmasına olanak sağlar. Hareketin açıklığı ve hızı ayarlanarak, erken dönemde güvenli bir güçlendirme sağlanabilir. Su içinde hareket etme ile oluşan türbülans, propriosepsiyon ve denge reaksiyonlarını uyarır (6-9). Ayrıca tedavinin erken dönemlerinde yardımsız egzersiz yapabilme olanağı, ağrıda azalma, hareketlerin kolaylaşması gibi faktörler hastanın uyumunu, başarma inancını ve tedaviye olan güvenini artırır (8).

\section{Osteoporozlu Hastalarda Su İçi Egzersizlerin Önemi}

Su içi egzersizler, kemikler üzerinde yük bindirici etkiyi azalttığı için OP'lu hastalara önerilen klasik egzersizlerden değildir. Su içinde kemik üzerine binen yük potansiyeli genellikle, kemik kütlesini inşa etmek ya da korumak için yetersiz sayılır. Ancak, su fizyolojik ve fiziksel özellikleri nedeniyle ideal bir egzersiz ortamıdır. Hidrostatik basınç ve viskozite egzersiz boyunca sürtünme ya da direnç sağlar. Böylece su, daha fazla fiziksel aktivite olanağı, kinestetik feedback ve güven duygusuyla beraber iskelette güçlenmeye yol açar. Suda egzersiz yaparken yerçekimi gücünün eksikliğine rağmen kemikte iyileşme olması bu şekilde açıklanabilir $(10,11)$.

Günümüzde sınırlı sayıdaki çalışmadan elde edilen veriler, su içi egzersizlerin var olan kemik kütlesinin devamı veya yapılanması için yeterli uyarı sağladığı yönündedir. Su içi egzersiz programına katılan postmenopozal kadınlarda kemik yoğunluğunda idame ya da artış eğilimi saptanırken, kontrol gruplarında azalma saptanmıştır $(12,13)$. Tolomio ve ark.'nın çalışmasında postmenopozal düşük kemik mineral yoğunluğu olan hastalara, yük bindiren ve yük bindirmeyen (su içi egzersiz) kombine egzersiz uygulanmış ve bunlar egzersiz yapmayan kontrol grubu ile karşılaştırılmıştır. DXA ölçümü (femur boynu T skoru) egzersiz uygulanan grupta istatistiksel olarak anlamlı artış göstermiştir. Ayrıca tedavi sonrasında kontrol grubunda falangeal ultrasonografi ile ölçülen kemik kalitesinde azalma tespit edilmiş, egzersiz grubunda ise saptanmamıştır (14). Benzer şekilde Ay ve ark. hem akuatik hem yük bindirici egzersizlerin kalkaneal BUA (Broadband Ultrasound Attenuation)'da artış sağladığını belirtmişlerdir (11).
Aynı yazarların bir diğer çalışmasında sedanter postmenopozal kadınlarda akuatik egzersizlerin kemik üzerinde anabolik etki sağladığı görülmüştür (15).

OP'lu hastalarda düşme ve buna bağlı kırık gelişimi, yüksek mortalite ve morbidite riski yanında ekonomik yük nedeniyle önemli bir problemdir. Düşmenin önlenmesi için eğitim, çevre düzenlenmesi, davranışsal modifikasyon ile denge ve kas gücünü geliştiren egzersizler gibi multidisipliner yaklaşım gereklidir $(16,17)$. Su ise, düşme korkusunu ve düşmeye bağlı incinmeleri azaltan güvenli bir egzersiz ortamı sağlar.

Bazı çalışmalar düşme riskini azaltmak için özellikle dengenin iyileştirilmesi istendiğinde su içi egzersizlerin de uygun olduğunu belirtmektedir. Arnold ve ark.'nın çalışmasında OP'lu hastalar su içi egzersiz, kara egzersizi ve egzersiz yapmayan grup olarak sınıflandırılmıştır. Su içi egzersiz grubunda kara egzersiz grubuna göre, geriye tandem (topuğun diğer ayağın parmaklarına değdirilmesi) yürüyüş şekli ile ölçülen dengede istatistiksel olarak anlamlı düzelme saptanmıştır (18). Ayrıca su içi egzersizlerin denge üzerine etkileri basamak testi ile değerlendirilmiş ve kontrol grubuna göre su içi egzersiz grubunda anlamlı iyileşme saptanmıştır $(19,20)$. OP'a bağlı kırıkların başka bir sonucu da yaşam kalitesini olumsuz etkilemesidir (16). Su içi egzersizlerin bir avantajı da yaşam kalitesi üzerinde pozitif etki göstermesidir. Su içi egzersizlerin yaşam kalitesi üzerine etkisini Kısa Form-36 (SF36) ile değerlendiren bir çalışmada, tedavi programı sonrasında su içi egzersiz grubunda ölçeğin tüm alt gruplarında (20); başka bir çalışmada ise fiziksel fonksiyon, canlılık, sosyal fonksiyon ve mental sağlık alt ölçeklerinde iyileşme (19) sağlamıştır. Değerlendirme parametresi olarak OP yaşam kalitesi sorgulamasının (OP QOL) kullanıldığı bir başka araştırmada ise su içi egzersiz grubunda egzersiz yapmayan kontrol grubuna göre fark saptanmamıştır (18).

Su içi egzersizler ayrıca depresyon (20), psikolojik iyilik hali (21), esneklik, kardiyovasküler dayanıklılık ve fiziksel fonksiyonel kapasite üzerinde olumlu etki göstermiştir $(14,21)$.

\section{Sonuç}

OP için önerilen yük bindirici egzersizler hastada ağrı ve rahatsızık yaratabilir. Bu nedenle su ideal bir egzersiz ortamı sağlamaktadır. Düşme ve buna bağlı incinme riskini azaltan, ağırlıksızlık etkisi ile eklemlere binen yükü azaltıp eklem hareket açıkığını ve esnekliğini arttıran, postural ve denge reaksiyonlarını uyaran, su direnci ile güçlendirme sağlayan su içi egzersizler; düşme korkusu, denge bozuklukları, ağrı ya da motivasyon eksikliği gibi nedenlerle kara egzersizlerini yapmakta zorlanan OP'lu hastalar için uygun seçenektir. Su içi egzersizler bu grup hastada kemik yoğunluğunda idame ya da artış eğilimi sağlamakta, dengeyi iyileştirerek düşme riskini azaltmakta ve yaşam kalitesi üzerinde olumlu etki yapmaktadır.

\section{Kaynaklar}

1. Sipos $W$, Pietschmann P, Rauner M, Kerschan-Schindl K, Patsch J. Pathophysiology of osteoporosis.Wien Med Wochenschr 2009;159:230-4.

2. Vilela P, Nunes T. Osteoporosis. Neuroradiology 2011;53:S185-9.

3. Sandhu SK, Hampson G. The pathogenesis, diagnosis, investigation and management of osteoporosis. J Clin Pathol 2011;64:1042-50.

4. Howe TE, Shea B, Dawson LJ, Downie F, Murray A, Ross C, et al. Exercise for preventing and treating osteoporosis in postmenopausal women. Cochrane Database Syst Rev 2011;CD000333. 
5. Barron P. Properties of Water. In: Barron P, editor. Hydrotherapy Theory and Technique. 3.th ed. Pine Island Publishes; 2003. p. 23-7.

6. Vargas LG. Introduction to Aquatic Therapy. In: Vargas LG, editor. Aquatic Therapy Interventions and Applications.Washington, Idyll Arbor, Inc.; 2004. p. 3-38.

7. Becker BE. Biophysiologic Aspects of Hydrotherapy. In: Cole AJ, Becker $\mathrm{BE}$, editors. Comprehensive Aquatic Therapy. 2.th ed. Philedelphia, Butterworth Heinemann, Elseiver; 2004. p. 19-53.

8. Koury JM. Introduction: Benefits of an Aquatic Therapy Program. In: Koury JM, editor. Aquatic Therapy Programming Guidelines for Orthopedic Rehabilitation. United States of America, Human Kinetics; 1996. p. 1-11.

9. Irion JM. Aquatic Properties and Therapeutic Interventions. In: Brody LT, Geigle PR, editors. Aquatic Exercise for Rehabilitation and Training. United States of America, Human Kinetics; 2009. p. 25-35.

10. June Lindle. Aquatic Exercise Association, A resource Manual For Aquatic Fitness Professionals. Nokomis, FL: Human Kinetics; 2006.

11. Ay A, Yurtkuran M. Influence of aquatic and weight-bearing exercises on quantitative ultrasound variables in postmenopausal women. Am J Phys Med Rehabil 2005;84:52-61.

12. Rotstein $A$, Harush $M$, Vaisman $N$. The effect of a water exercise program on bone density of postmenopausal women. J Sports Med Phys Fitness 2008:48:352-9.

13. Tsukahara N, Toda A, Goto J, Ezawa I. Cross-sectional and longitudinal studies on the effect of water exercise in controlling bone loss in Japanese postmenopausal women. J Nutr Sci Vitaminol (Tokyo) 1994;40:37-47.
14. Tolomio S, Ermolao A, Lalli A, Zaccaria M. The effect of a multicomponent dual-modality exercise program targeting osteoporosis on bone health status and physical function capacity of postmenopausal women. J Women Aging 2010;22:241-54.

15. Ay A, Yurtkuran M. Evaluation of hormonal response and ultrasonic changes in the heel bone by aquatic exercise in sedentary postmenopausal women. Am J Phys Med Rehabil 2003;82:942-9.

16. Ip TP, Leung J, Kung AW. Management of osteoporosis in patients hospitalized for hip fractures. Osteoporos Int 2010;21:S605-14.

17. Gillespie LD, Robertson MC, Gillespie WJ, Lamb SE, Gates S, Cumming $R G$, et al. Interventions for preventing falls in older people living in the community. Cochrane Database Syst Rev 2009:CD007146.

18. Arnold CM, Busch AJ, Schachter CL, Harrison EL, Olszynski WP. A Randomized Clinical Trial of Aquatic versus Land Exercise to Improve Balance, Function, and Quality of Life in Older Women with Osteoporosis. Physiother Can 2008;60:296-306.

19. Devereux K, Robertson D, Briffa NK. Effects of a water-based program on women 65 years and over: a randomised controlled trial. Aust J Physiother 2005;51:102-8.

20. Solak O, Dündar U, Cakır T, Ozbulut O, Babaoglu US, Toktas H, et al. Comparison of water-based and land-based exercise programs on postmenopausal women with osteoporosis. Neurology, Psychiatri and Brain Research 2008:15:45-50.

21. Bravo G, Gauthier P, Roy PM, Payette H, Gaulin P. A weight-bearing, water-based exercise program for osteopenic women: its impact on bone, functional fitness, and well-being. Arch Phys Med Rehabil 1997;78:1375-80. 